\title{
Punching Shear Strength Model for RC Slab-Column Connection Based on Multiaxial Strength Theory of Concrete
}

\author{
H. Y. PANG ${ }^{1, a}$, Z. J. WANG ${ }^{1, b}$, C. T. HUANG ${ }^{2, c^{*}}$, S. $\mathrm{PU}^{2, d}$ \\ ${ }^{1}$ College of Civil Engineering, Chongqing University, Chongqing, P. R. China \\ ${ }^{2}$ School of Engineering and Technology, Zunyi Normal College, Zunyi, P. R. China \\ ahypany@126.com, bjwwang@cqu.deu.cn, chuangct@yeah.net, ${ }^{\mathrm{d}}$ pushuangss@yeah.net
}

Keywords: Structural engineering, Slab-column connection, Punching, Strength model.

\begin{abstract}
A strength model was presented to give the mechanical explanation of the punching phenomenon, and to predict the punching shear strength of the interior reinforced concrete (RC) slab-column connection without shear reinforcement. The model assumes that the punching shear force is resisted mainly by the shearing-compression zone of a critical crack section, and the punching shear strength is determined as the minimum load among the loads which are obtained by the intersection of the demand curve and the capacity curve of each given flexure crack. The crack corresponding to the punching shear strength is defined as the critical crack. The capacity curve is obtained by the layer model of shearing-compression zone based on the biaxial strength theory of concrete. The demand curve is defined by equilibrium of forces in slab sector. For verification, the developed strength model was applied to existing test specimens tested by other researchers.
\end{abstract}

\section{Introduction}

RC flat plate structure has proven to be the most appropriate slab system for buildings. However, the flat plate structure is susceptible to punching shear failure at slab-column connection under flexure-shear composite forces. Once punching shear failure happens, it makes gravity redistribution, worse still, the structure may undergoes progressive collapse [1,2].

A databank which comprised of 519 tests was collected by Ospina et al. [3]. On this basis, Huang [4] collected additional 159 tests which were reported in Chinese and Japanese and missed by Ospina, thus updating the databank to 678 test specimens. These test results provide reference for the development, verification and evaluation of punching shear design provisions. However, there are divergences among design provisions of various countries in aspects of location and shape of the critical section, calculation method of the nominal stress, value of the ultimate stress and other controlling factors [4-6].

In the present study, to provide a theoretical background for the punching shear strength of RC slab-column connections, a new punching shear strength model based on multiaxial strength theory of concrete was presented. This strength model theoretically describes the propagation of flexure-shear crack, the punching failure criterion and the critical crack judgment method.

\section{Punching Shear Strength Model}

In a slab subject to a concentrated load with the boundary supported, the flexure cracks will appear from the column edge to support gradually. Each flexure crack corresponds to the specific shearing-compression zone and shear strength and each flexure crack is likely to become the critical crack. Fig. 1 shows the solution of the punching shear strength model, the shear strength $V$ of each crack is determined at the intersection $(1,2, k \ldots)$ between the capacity curve (which decreases with the deformation $\psi$ ) and the demand curve (which increases with the deformation $\psi$ ). The flexure crack section where the shear strength is minimum becomes the critical section.

To determine the punching shear strength, the capacity curve and the demand curve of each crack must be defined. In the present study, the biaxial strength criteria of concrete, the refined 
shearing-compression layer model, the distribution of the curvature, the judgment of the critical section and the consideration of size effect and dowel action will all described below, all these fundamental elements constitute the punching shear strength model.

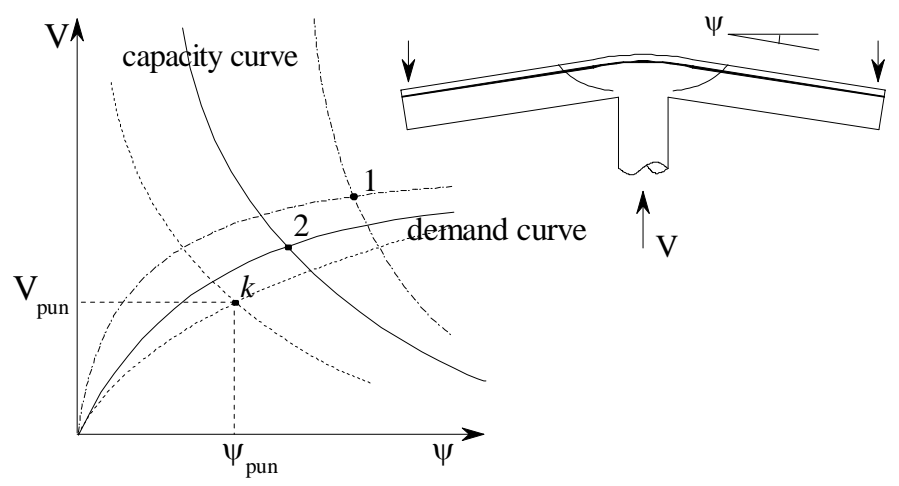

Fig. 1 Capacity curve and demand curve.

Failure Criteria and Constitutive Model. In the present study, from the tests phenomenon, the flexure crack will be prior to the punching failure, and once the flexural crack initiates, the applied shear force is resisted mainly by the shearing-compression zone which is below the neutral axis.

The shearing-compression zone of a slab-column connection has a three-dimensional stress due to radial compression, tangential compression and normal shearing (Fig. 2a). Although the interaction among stress components must be considered accurately to evaluate the punching shear strength, according to Kupfer et al. [7] and Chen [8], the concrete tensile strength under triaxial compressioncompression-tension is not likely to be significantly different from that under biaxial compressiontension. For these reasons, in the proposed method, it is assumed the three-dimensional stress was simplified as biaxial compression-shear stresses (Fig. 2b).

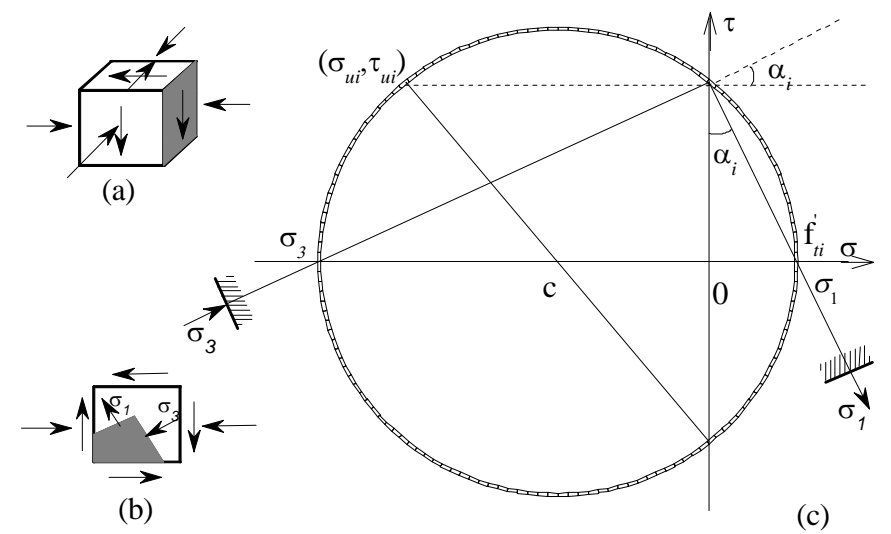

Fig. 2 Failure criteria of concrete.

According the assumption, to define the failure criteria of the shearing-compression zone, the principal stress failure criteria [8] were used:

$$
\sigma_{3}^{1}=\frac{\sigma_{i}}{2} \pm \sqrt{\left(\frac{\sigma_{i}}{2}\right)^{2}+\tau_{i}^{2}} .
$$

where, $\sigma_{i}$ is the compressive normal stress and $\tau_{i}$ is the shear stress of arbitrary micro-unit $i, \sigma_{1}$ and $\sigma_{3}$ are the principal compressive and tensile stresses, respectively. The positive direction of $\sigma_{3}$ is tension and the positive direction of $\sigma_{1}$ has shown in Fig. 2b. According to the theory of plasticity [8], when $\sigma_{1}>f_{t}^{\prime}\left(f_{t}^{\prime}>0\right)$ or $\left|\sigma_{3}\right|>\left|f_{c}^{\prime}\right|\left(f_{c}^{\prime}<0\right)$, the micro-unit concrete gets failure. Therefore, the maximum shear stress capacity $\tau_{u i}$ for arbitrary micro-unit $i$ under compressive normal stress $\sigma_{u i}$ can be defined as a function of $\sigma_{u i}$ : 


$$
\tau_{u i}=\min \left(\sqrt{f_{c i}^{\prime}\left(f_{c i}^{\prime}-\sigma_{u i}\right)}, \sqrt{f_{t i}^{\prime}\left(f_{t i}^{\prime}-\sigma_{u i}\right)}\right) .
$$

where, $f_{t}$ and $f_{c}$ are the revised tensile and compressive strength of the concrete in biaxial compression-tension stress, respectively. According to Kupfer et al. [7], in the present study, $f_{c i}$ and $f_{t i}$ can be defined simplified as:

$$
\left\{\begin{array}{c}
f_{t i}^{\prime}=\frac{f_{t}}{1-0.8\left(f_{t} / f_{c}\right)\left(\sigma_{3 i} / \sigma_{1 i}\right)} . \\
f_{c i}^{\prime}=\left(\sigma_{3 i} / \sigma_{1 i}\right) f_{t i}^{\prime}
\end{array}\right.
$$

where, $f_{c}(>0)$ and $f_{t}(>0)$ are the nominal compressive and tensile strength of the concrete, $\sigma_{1 i}$ and $\sigma_{3 i}$ are the principal compressive and tensile stresses of arbitrary micro-unit $i$, respectively.

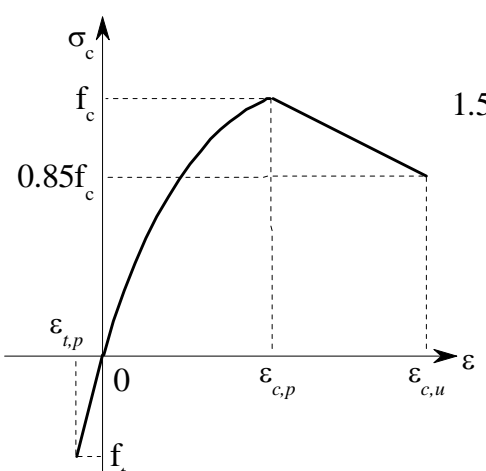

(a)

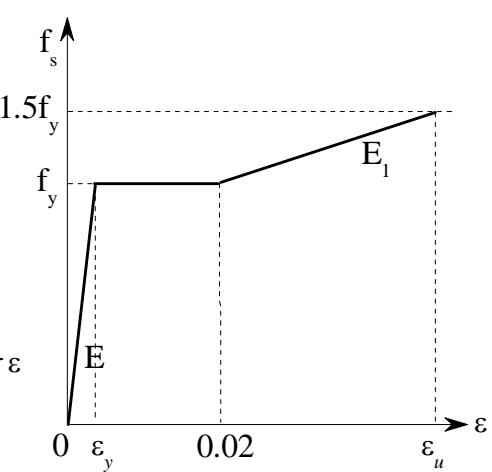

(b)

Fig. 3 Typical stress-strain curve for concrete and steel.

The present study focuses on the slab-column connections without shear reinforcement, there is no strong constraint with the concrete, therefore, the Hognestad model (Fig. 3a) is adopted. Considering the hardening stage, the reinforcement adopts the trilinear model (Fig. 3b), where $\varepsilon_{u}=0.1, \varepsilon_{y}=f_{y} / E$, $E_{1}=6.25 f_{y}$, when there is no test data for elasticity modulus $E, E=200 \mathrm{GPa}$.

The Layer Model of the Shearing-Compression Zone. Park et al. [9] developed an analytical method employing the layer model to predict the shear strength of prestressed concrete beams. In the present study, to define the failure mechanism of the compression zone subject to the combined stresses, the theory of plasticity and the refined layer model were proposed.

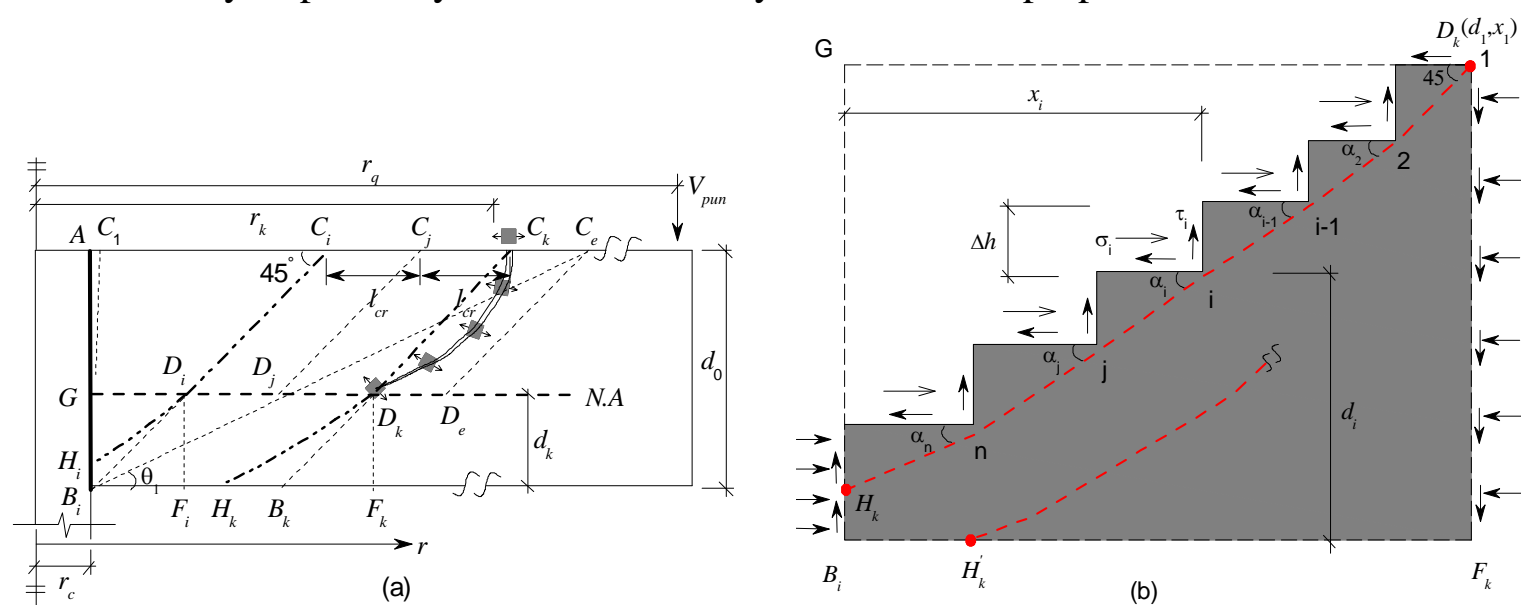

Fig. 4 Development of the punching crack.

As show in Fig. 4a, a flexure-shear crack initiates at a location $r=r_{k}$ and propagates to the neutral axis at $D_{k}$. As the crack penetrated into the shearing-compression zone, compressive normal stress increases and shear stress decreases, thus the flexure-shear crack becomes close to the longitudinal axis, as $D_{k} H_{k}$ shown in Fig. 4 a. 
Fig. $4 \mathrm{~b}$ shows the refined layer model of shearing-compression zone $D_{k} F_{k} B_{i} G$, and the depth of the shearing-compression zone $\left(d_{k}\right)$ was divided into $n$ layers with uniform thicknesses. In the proposed refined layer model, considering the softening of concrete, once the compressive normal stress $\left|\sigma_{u i}\right|>\left|f_{c i}\right|$, the shear stress capacity $\tau_{u i}$ of the concrete layer $i$ is zero. For developing a practical analysis method, it was assumed that all the concrete layers along the crack reach their shear stress capacity $\tau_{u i}$ simultaneously.

When the crack propagates within the slab, the $\tau_{u i}$ can be determined by the shear capacity controlled by shearing, from Eq. 2 and Eq. 3, the $\tau_{u i}$ is defined as a function of compressive normal stress:

$$
\left\{\begin{array}{l}
f_{t i}^{\prime}=\frac{f_{t}+0.8 f_{t} / f_{c} \cdot \sigma_{u i}}{1+0.8 f_{t} / f_{c}} \\
\tau_{u i}=\sqrt{f_{t i}^{\prime}\left(f_{t i}^{\prime}-\sigma_{u i}\right)}
\end{array} .\right.
$$

While when the inclined flexure-shear crack reaches the column edge $\left(r=r_{c}\right)$, it assumed $\tau_{u i}$ controlled by compression:

$$
\tau_{u i}=\sqrt{f_{c}\left(f_{c}+\sigma_{u i}\right)} \text {. }
$$

When the crack propagates within the slab, according to the Mohr's circle (Fig. 2c), the orientation $\left(\alpha_{i}\right)$ of the inclined flexure-shear crack at each layer was calculated as follows:

$$
\alpha_{i}=\operatorname{acrtg} \frac{f_{t i}^{\prime}}{\tau_{u i}} .
$$

where, $f_{t i}$ and $\tau_{u i}$ are calculated from Eq. 4, it can be noted that the orientation of all the point along the crack propagated within the slab is restricted only by compressive normal stress $\sigma_{u i}$. Once the crack reach column edge, as explanted above, the crack will sequentially propagate along the column edge.

As Fig. $4 \mathrm{~b}$ shows, $x_{i}$ and $d_{i}$ are the distance from the layer to the column edge and to the slab bottom, respectively. To obtain the whole crack location, there should know the coordinate $\left(x_{i}, d_{i}\right)$ of all points along the flexure-shear crack, that is:

$$
\left\{\begin{array}{c}
x_{i}=x_{1}-\sum_{l=1}^{i-1} \frac{\Delta h}{\operatorname{tg} \alpha_{l}} \\
d_{i}=d_{1}-(i-1) \Delta h \\
v_{i}=2 \pi\left(r_{c}+x_{i}\right) \cdot \Delta h \cdot \tau_{u i}
\end{array}\right.
$$

where $\Delta h$ is the layer thickness, $x_{1}$ and $d_{1}$ are the coordinate of the start point of the shearing-compression zone (i.e. $D_{k}$ in Fig. 4 , in the present study, for developing a practical analysis method, the height of the neutral axis $d_{k}$ can be calculated by the slab radial curvature $\varphi_{j}$. The straight line $C_{k} D_{k}$ with inclination of $45^{\circ}$ intersected with the neutral axis at $D_{k}$ and $D_{k}$ is the start point of shearing-compression zone.), $r_{c}$ is the radius of the column, $v_{i}$ is the shear strength capacity of each layer, thus the punching shear strength of the slab-column connection is $V_{\text {pun }}=\Sigma v_{i}$.

To solve Eq. 7, the compressive normal stress $\sigma_{u i}$ of each point $i$ along the crack should be known, that is the radial curvature $\varphi_{i}$ of the section $i$ should be known.

Distribution of the Curvature. Based on the results of experiment and FEM, in the present study, when the column edge reinforcement not yielded, the distribution of radial curvature $\varphi_{r}$ and tangential curvature $\varphi_{t}$ are calculated by elastic shell theory [10]. While, when the column edge reinforcement yields (i.e. the column edge section moment reaches the yield moment $M_{y}$, and the column edge curvature $\varphi_{j}$ is larger than yield curvature $\varphi_{y}$ ), it assumes that in the region of $r \leq r_{\mathrm{c}}+d, \varphi_{r}=\varphi_{t}=\varphi_{j}$, and in the remainder region, $\varphi_{r}$ is calculated by the elastic shell theory [10], $\varphi_{t}=\varphi_{j^{*}}\left(r_{c}+d\right) / r(r$ is the section radius). 
Determine the Punching Failure Section (Critical Crack). As the load increased, the momentgradient will increase and the column edge section will appear flexure crack firstly (as $C_{1}$ in Fig. 4a). And then, because of the bond failure between concrete and steel, the flexure cracks will appear from the column edge to support gradually. In the present study, the average crack spacing $\left(l_{c r}\right.$, shown as in Fig. 4a) is calculated as: $l_{c r}=(80+0.0425 d l \rho) \cdot \beta$, where $d$ is steel diameter $(\mathrm{mm}), \rho$ is the reinforcement ratio and $\beta=1.0$ for plain bar, $\beta=0.7$ for ribbed bar. And the radius $r_{k}$ of arbitrary flexure crack $k$ is: $r_{k}=\min \left(l_{c r}, d_{0}\right)+l_{c r} \cdot(k-1)$, where $d_{0}$ is the effective height of slab, $k(=1,2,3 \ldots)$ is the sequence number of flexure crack.

Size Effect and Dowel Action. Many researchers have studied the affection of size effect to the punching behavior of slab-column connection and have confirmed the necessity of considering the size effect. Birkle and Dilger [11] studied the influence of slab thickness on the punching shear strength of flat slabs by tests and clearly demonstrated the significant effect of size on the shear stress resistance, without regard the reinforcement ratio (considered in refined layer model), the size factor can be approximated by $s e=(d / 200)^{-1 / 2} \geq 0.5$. In the present study, the size factor suggested by Birkle and Dilger was adopted.

Jelic et al. [12] indicated that, area not diameter of steel influenced the punching capacity. In addition, it should be noticed that once the steel which intersect with crack yielded, the dowel action would be decreased, the phenomenon confirmed by experiment and many researchers, thus, the steel stress should be considered when computing the dowel action. The dowel mechanism fails due to horizontal or vertical longitudinal splitting cracks and yielding of the bar. Based on the above conclusions, the yield strength and stress level of bar, tensile strength of concrete, area of bar should be considered when computing the dowel action. In the present study, approach proposed by CEB-FIP model code was adopted:

$$
V_{\text {dow }}=\frac{2 A_{c} \rho}{\pi} \sqrt{f_{c} f_{y}\left(1-\varsigma^{2}\right)} \sin \alpha .
$$

where, $A_{c}$ is the area of the section crossing the punching crack, $\zeta=\sigma_{s} / f_{y}$ and $\sigma_{s}$ is the axial tensile stress in the reinforcing bar characterized by a yield strength $f_{y}, \rho$ is reinforcement ratio, $\alpha$ is the inclination of punching crack.

\section{Capacity Curve and Demand Curve}

In the present study, the calculation method of load $\left(V_{\text {cap }}\right)$ and rotation $\left(\psi_{\text {cap }}\right)$ of capacity curve has described above and shown in Fig. 6 . To calculate the load $\left(V_{d e m}\right)$ and rotation $\left(\psi_{d e m}\right)$ of demand curve, select the sector slab as isolation block when the slab-column connection bear the punching load. The distribution stress of concrete and steel, the resultant force and the diagram of force balance were shown in Fig. $5 \mathrm{a}, 5 \mathrm{~b}$ and $5 \mathrm{c}$, respectively. The central angle of sector block is $\Delta \phi$, according to the force equilibrium in Fig. 5c, the moment equilibrium is

$$
V \frac{\left(r_{q}-r_{c}\right)}{2 \pi}=m_{r}\left(r_{k}\right) r_{k}+\int_{r_{k}}^{r_{s}} m_{t}(r) d r .
$$

where, $m_{r}\left(r_{k}\right)$ and $m_{t}(r)$ are the radial moment at the flexure-shear crack (which radius is $r_{k}$ ) and the tangential moment from $r_{k}$ to $r_{s}$, both $m_{r}\left(r_{k}\right)$ and $m_{t}(r)$ can be obtained from moment-curvature curve with the curvature distribution which achieved above. The demand load $V^{j k}{ }_{d e m}$ in demand curve which represents the punching load corresponding an arbitrary flexure-shear crack $r_{k}$ and column edge curvature $\varphi_{j}$ can be obtained from Eq. 9 .

According to the material property, specimen geometric dimension and the constitutive model selected in this study, the ultimate curvature of RC section $\varphi_{u}$ can be obtained easily by iterating, and once $\varphi_{j}$ (curvature at the column edge, shown as in Fig. 6) reaching $\varphi_{u}$, the whole iteration is over. As shown in Fig. 6, there are specific capacity curve and demand curve of punching load-rotation relationship for each flexure-shear crack, and the corresponding punching load and rotation $\left(V_{k}, \psi_{k}\right)$ 
can be obtained from the cross point of the two curves. The final punching load $V_{\text {pun }}$ of slab-column connection is the minimum punching value among all the flexure-shear crack.

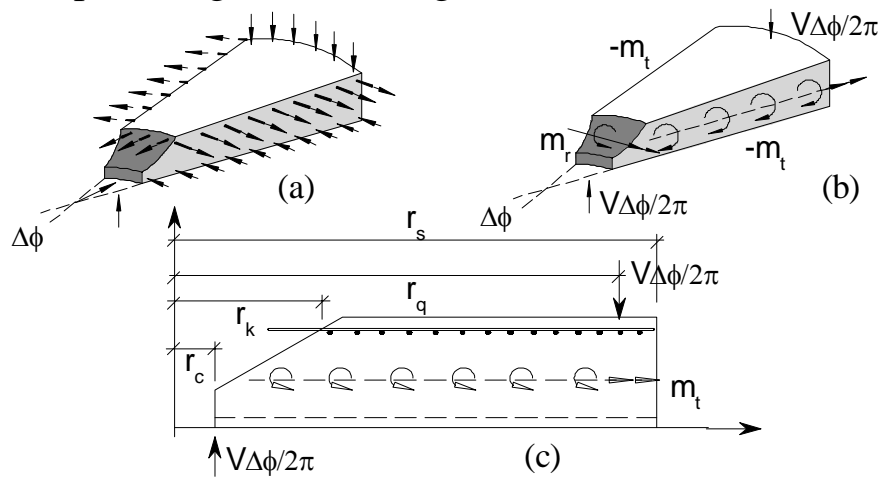

Fig. 5 Sector model for demand curve.

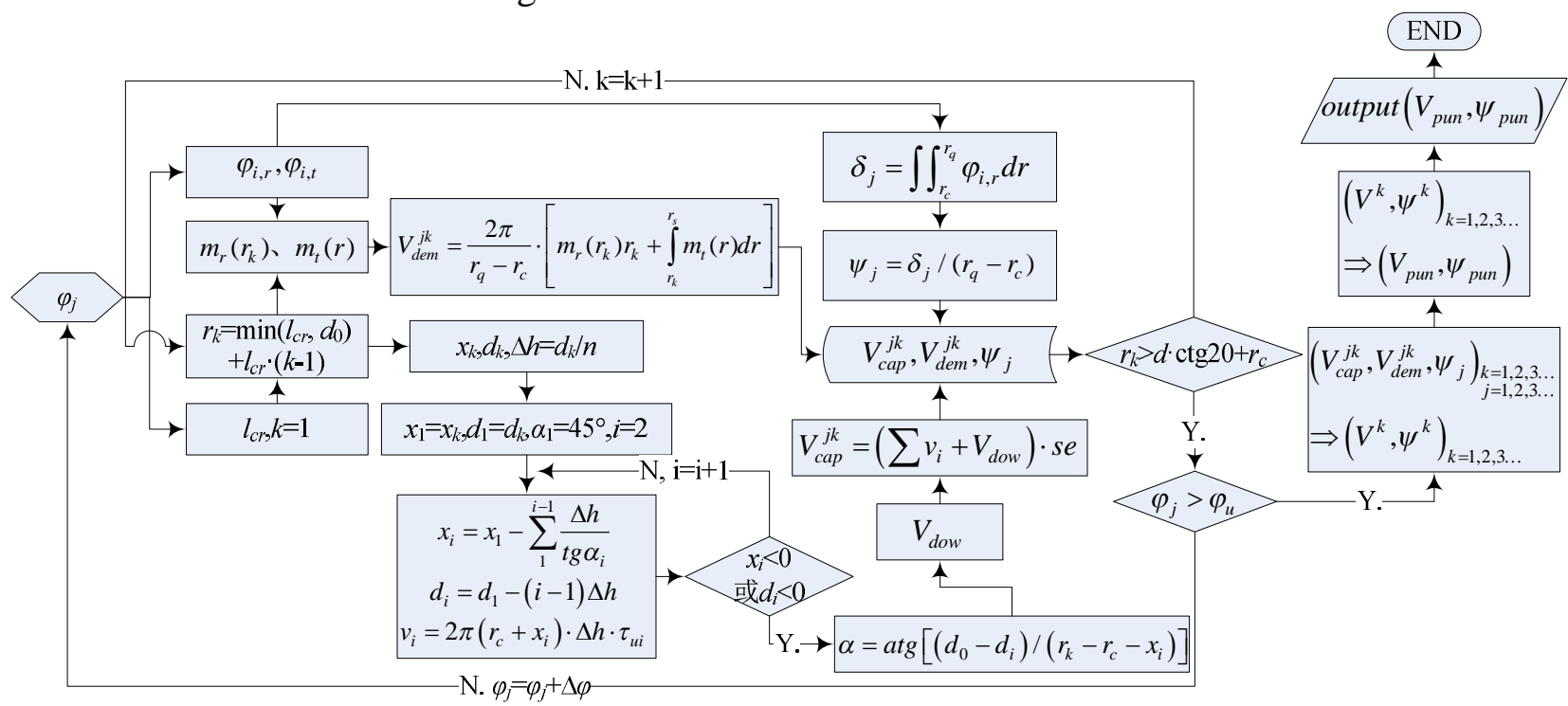

Fig. 6 Flow chart of punching shear strength method.

\section{Verification}

Table 1. Calculation results of punching shear strength.

\begin{tabular}{ccc}
\hline Calculate method & AVG & COV \\
\hline Presented method in this paper & 0.992 & 0.143 \\
GB50010-2010 & 1.270 & 0.245 \\
ACI318-11 & 1.456 & 0.234 \\
CEB/FIP MC2010 & 2.333 & 0.362 \\
BS 8110-97 & 1.244 & 0.111 \\
CAN/CSA A23.3-04 (R2010) & 1.264 & 0.234 \\
EN 1992-1-4: 2004 & 1.144 & 0.130 \\
DIN 1045-1: 2008 & 1.192 & 0.129 \\
JSCE2002 & 1.017 & 0.154 \\
\hline
\end{tabular}

The author collected 678 tests [4], all these specimens can be categorized in 8 main types according to the test set-up and the specimen geometry. A total of 37 standard specimens with failure deflection (or rotation) and failure load report from 4 literatures (Ramdane,1996; Kinnunen \& Nylander, 1960; Hallgren, 1996; Regan, 1986) were used to verify the model. Here, standard specimen refers to the circle plate specimen, loaded or supported by cylinder and annular boundary. The average value (AVG) and coefficient of variation $(\mathrm{COV})$ of $V_{\text {test }} / V_{\text {model }}$ are shown in Table 1 . In this table, eight mainstream specifications for the punching shear strength were also evaluated. Obviously, the presented method gives more accurate results than the others. 


\section{Conclusion}

This paper focused on the theoretical method which can be used to predict the punching shear strength. Based on the phenomenon of punching shear tests and multiaxial strength theory of concrete. The punching shear strength model, including the determination of the critical crack and the punching strength, was presented. The verification results indicated that this theoretical model has good accuracy.

\section{Acknowledgments}

This study was funded by research grant from the Doctoral Program Foundation of Zunyi Normal College (BS[2015]17\#) and Science and Technology Department of Guizhou Province (LH[2016]7005), which are gratefully acknowledged.

\section{References}

[1] S. King, N. J. Delatte, Collapse of 2000 Common wealth Avenue: punching shear case study, J. Perform. Constr. Facil. 18(1) (2004) 54-61.

[2] G. Birkle, Punching of Flat Slabs: The Influence of Slab Thickness and Stud Layout, Department of Civil Engineering, University of Calgary, Calgary, AB, Canada, 2004.

[3] C. E. Ospina, G. Birkle, W. Widianto, ACI 445 Punching Shear Collected Databank. Network for Earthquake Engineering Simulation (database), Dataset, (2011) DOI:10.4231/D3TX35618.

[4] C. T. Huang. Study on the Analysis Methods of Hollow Floor and Punching Issues of Slab-column Connection, $\mathrm{PhD}$ thesis, School of Civil Engineering, Chongqing University, Chongqing, China, 2015.

[5] S. Hamada, Q. Yang, M. Mao. Evaluation of punching shear strength of reinforced concrete slabs based on database, J. Adv. Concr. Tech. 6(1) (2008) 205-214.

[6] N. J. Gardner, Verification of Punching Shear Provisions for Reinforced Concrete Flat Slabs, ACI Struct. J. 108(5) (2011) 572-580.

[7] H. Kupfer, H. K. Hilsdorf, H. Rusch, Behavior of concrete under biaxial stresses, ACI J. Proc. 66(8) (1969) 656-666.

[8] W. F. Chen. Plasticity in reinforced concrete. J. Ross Publishing, 2007.

[9] H. G. Park, S. Kang, K. K. Choi, Analytical model for shear strength of ordinary and prestressed concrete beams, Eng. Struct. 46 (2013) 94-103.

[10] S. Timoshenko, S. Woinowsky-Krieger, Theory of plates and shells. New York: McGraw-hill, 1959.

[11]G. Birkle, W. H. Dilger. Influence of slab thickness on punching shear strength, ACI Struct. J. 105(2) (2008) 180-188.

[12]I. Jeli, M. N. Pavlović, M. D. Kotsovos. A study of dowel action in reinforced concrete beams, Mag. Concr. Res. 51(2) (1999) 131-141. 